\title{
Bases sócio-culturais do controle social em saúde indígena. Problemas e questões na Região Norte do Brasil
}

\author{
The sociocultural basis for indigenous peoples' \\ health advocacy. Problems and issues in the \\ Northern Region of Brazil
}

Luiza Garnelo 1

Sully Sampaio 1

1 Núcleo de Estudos
em Saúde Pública,
Departamento de Saúde
Coletiva, Faculdade
de Ciências da Saúde,
Universidade do Amazonas.
RuaDr.Afonso Pena
1053, Manaus, AM
69020-160, Brasil.
lgarnelo@hotmail.com
souzasampaio@hotmail.com

\begin{abstract}
This article discusses the sociocultural basis for indigenous peoples' health advocacy in Brazil. The discussion follows two main lines of reasoning: (1) advocacy or "social control" at the local level and the functioning of local or district-level health councils and (2) the interface between the relations among large indigenous peoples' organizations in the Northern Region of Brazil and the managers of public policies for indigenous peoples' health. The information was gathered through participatory observation in regional and national health meetings and follow-up on local and district-based health councils. The article demonstrates the reinforcement of the ethnic/political movement generated by the partnership with the Ministry of Health and the contradictions generated by measures affecting indigenous peoples' health.

Key words Local Health Systems; South Americans Indians; Social Control Policies

Resumo O trabalho discute as bases sócio-culturais do controle social em saúde indígena. A reflexão pauta-se em dois eixos principais: (1) o exercício do controle social no plano local e no funcionamento de conselhos locais ou distritais de saúde e (2) a interface das relações travadas entre as grandes organizações indígenas na Região Norte do Brasil e os gestores das políticas públicas de saúde indígena. As informações foram coletadas por meio de observação participante em encontros regionais e nacionais de saúde, reuniões e acompanhamento a conselhos locais e distritais de saúde. Demonstram-se o reforço do movimento etnopolítico gerado pela parceria com o Ministério da Saúde e as contradições geradas pela terceirização das ações de saúde indígena.

Palavras-chave Sistemas Locais de Saúde; Índios Sul-Americanos; Políticas de Controle Social
\end{abstract}




\section{Introdução}

A presente discussão enfoca as atividades políticas de saúde indígena na Região Norte do Brasil, e baseia-se em informações coletadas por meio de observação participante durante reuniões de conselhos distritais e locais dos seguintes Distritos Sanitários: Rio Negro, Alto Solimões, Médio Solimões e Manaus, além de reuniões da Comissão Intersetorial de Saúde Indígena, encontros de profissionais indígenas de saúde, encontros de saúde promovidos pelas organizações indígenas, reuniões preparatórias para a Conferência de Saúde Indígena e a III Conferência Nacional de Saúde Indígena. Também foram analisados os documentos referentes à implantação do Distrito Sanitário de Manaus, enviados à Coordenação das Organizações Indígenas da Amazônia Brasileira (COIAB), por lideranças de aldeias e as atividades de capacitação de conselheiros indígenas de saúde, efetuadas pela equipe do Projeto Rede Autônoma de Saúde Indígena (RASI) da Universidade do Amazonas, nas quais os ricos momentos de interação cotidiana com esses protagonistas das políticas de saúde, ofereceram um auxílio inestimável para o entendimento do dia-a-dia dos conselhos e conselheiros.

A temática aqui discutida será tratada em dois eixos: o primeiro se refere ao exercício do controle social no plano local e no funcionamento de conselhos locais ou distritais de saúde, e o segundo, tratará do plano político mais geral, na interface das relações travadas entre as grandes organizações indígenas na Região Norte do Brasil e os gestores das políticas públicas de saúde indígena.

Alguns conceitos básicos devem ser explicitados antes da discussão. O primeiro deles é o de organização indígena, aqui caracterizada como forma institucionalizada de expressão do movimento etnopolítico no Brasil, buscando o protagonismo político por meio da defesa dos interesses dos grupos indígenas. As lutas étnicas podem ser consideradas espaços de disputa de relações simbólicas, através das quais se busca a conservação ou a transformação das correlações de força na sociedade, e uma neutralização simbólica e material das desigualdades sociais. As atividades das organizações indígenas vêm articulando a realidade política das aldeias com forças exteriores a elas, inaugurando formas de luta centradas no direito à diferença étnica e no acesso a bens e serviços oriundos da aplicação de políticas públicas (Bartolomé, 1995). O segundo conceito chave é o de atividade política caracterizada por Oliveira Filho (1987:66) como “um processo público, pois abrange questões que afetam os interesses de grupos e não apenas de algumas pessoas em particular". Swartz et al. (1966:7) definiram a política como "o estudo dos processos envolvidos na determinação e implementação de objetivos públicos e na obtenção e uso de poder diferencial pelos membros do grupo relacionados com aqueles objetivos". Assim, o controle social deve ser entendido como uma forma de atividade política exercida pelas organizações indígenas em busca da obtenção, junto às instituições gestoras das políticas sanitárias, de espaços de poder a serem utilizados não apenas nas lutas pelo direito à saúde, mas também no contexto geral das relações interétnicas.

\section{Organização social e política indígena frente às demandas do sistema de saúde}

A saúde não se constitui como espaço autônomo, por isso o entendimento da complexidade deste campo social deve ser referido a questões mais gerais da cosmologia, da organização das sociedades indígenas e do exercício do poder político, entendido à luz das interações engendradas pelo processo colonizatório. Apesar das importantes diferenças nas formas de organização social dos povos indígenas amazônicos, autores como Clastres (1978, 1982), Rivière (1984), Overing (1983/1984) e Viveiros-de-Castro (1993), vêm produzindo estudos que permitem assinalar alguns aspectos comuns à maior parte deles, e que interessam à presente análise: o primeiro é a predominância do poder local, no qual as relações intra-aldeia ocupam um lugar de destaque no mundo indígena - quanto mais distante do plano local tanto mais rarefeitas se tornam as linhas de expressão do mesmo. Coerente com essa forma de expressão da sociedade, a chefia política indígena não costuma gozar de poder de mando. Conforme assinala a literatura (Clastres, 1978; Rivière, 1984), o chefe indígena caracteriza-se como um mediador de conflitos e distribuidor de bens, cuja capacidade de intervenção é fundada no diálogo, no convencimento dos liderados e no cumprimento das regras de reciprocidade entre grupos de parentesco. A legitimidade do poder político da liderança é garantida pela filiação a esse tipo de grupo social e o exercício da solidariedade é direcionado pelas regras de consangüinidade e/ou de afinidade; além disso, na Amazônia indígena, muitos grupos também concretizam sua organização social no controle de gênero e de geração.

A história do contato gerou um redimensionamento destes princípios, ao possibilitar a 
ampliação do espaço de poder da chefatura por meio do controle de bens e serviços auferidos em negociação com os não-índios. As transformações engendradas pelo processo colonizatório propiciaram o surgimento de mediadores das relações interétnicas, cujos papéis sociais são distintos daqueles desempenhados pelas chefias de aldeia, mas cuja legitimidade, ainda que mesclada a parâmetros como a escolaridade e conhecimento do mundo dos nãoíndios, também obedece aos princípios gerais que orientam o poder político local.

Essas características da organização social das sociedades indígenas têm importantes reflexos no desenvolvimento do controle social em saúde indígena. Dentre as principais inflexões produzidas pelas formas próprias do pensamento indígena assinalamos:

a) a legitimidade de ação de conselheiros nãoindígenas de saúde é fundada em critérios de elegibilidade e representatividade de grupos igualitários de cidadãos, em nome de quem podem tomar decisões. As sociedades indígenas não partilham a idéia de democracia representativa tipo grega; aqui a noção de representatividade não contempla a delegação de autoridade e da possibilidade de decidir pelos representados. O poder do chefe político indígena não tem alcance suficiente para a tomada de decisões que possam alterar a realidade social de seus liderados, e nem tem como garantir que suas decisões e acordos sejam por estes cumpridos. Como sua autoridade é centrada no uso da palavra, as "chefias" não conduzem os liderados conforme seus desejos, mas enunciam propostas e pontos de vista que podem ser considerados, seguidos ou rejeitados (Clastres, 1982). Tais características da chefia indígena são atualizadas nas suas modernas organizações, voltadas para a mediação do contato interétnico, que também são entidades sem poder de mando, mas com atribuições de ouvir, entender, explicar e sugerir rumos a tomar nas negociações com a sociedade nacional. Nesse caso, a delegação recebida destinase a uma intervenção intercultural mais eficiente junto ao mundo não-indígena, veiculando demandas coletivas que ultrapassam os interesses individualizados de cada aldeia (Bartolomé, 1995).

b) As obrigações de reciprocidade, oriundas do parentesco se expressam no dia-a-dia das entidades e nos conselhos de saúde. Nestes, o principal compromisso ético dos conselheiros é com as prioridades de seu grupo de parentes, por quem são pressionados para distribuir os bens que afluem a partir do sistema de saúde, em obediência à lógica redistributiva própria dos grupos indígenas amazônicos. A obrigação da chefia, de servir à sociedade, é atualizada na figura do dirigente de organização indígena e dos conselheiros de saúde, que devem distribuir bens e serviços, como combustível, medicamentos, motores de popa e cargos remunerados ou de prestígio, entre a parentela. No caso da saúde, tais demandas se confrontam com a lógica técnica, que orienta o planejamento das ações dos distritos sanitários e a distribuição dos insumos, de acordo com necessidades geradas pela presença e freqüência de doenças e composição demográfica da área de cobertura dos serviços. Os agentes de controle social ficam divididos entre as duas lógicas e cientes de que o não atendimento às solicitações oriundas do parentesco, pode gerar um desgaste político capaz de inviabilizar sua reeleição para os cargos representativos, seja no movimento indígena ou nos conselhos de saúde.

c) Autarquia e autonomia são valores caros à vida em aldeia, onde cada grupo deve ser capaz de prover sua própria subsistência e evitar formas de dependência entre clãs ou famílias; quando necessário, relações de interdependência são mantidas por meio de trocas ritualizadas. Tal estilo de vida é pouco compatível com noções técnicas como hierarquia e área de cobertura da rede de serviços, que orientam a organização das unidades em ordem de complexidade crescente, localizadas segundo requisitos de densidade demográfica, acessibilidade e presença de doenças, devendo oferecer atendimento a todos os grupos populacionais que formam sua área de abrangência. Na medida em que cada aldeia deseja controlar seus meios de reprodução social e que a implantação de uma unidade de saúde gera um incremento real no fluxo de bens e prestígio, sua localização em uma aldeia específica é interpretada, não como uma medida técnica racionalizadora de custos, e sim como um privilégio político da comunidade sede, instaurando relações de dependência entre o conjunto de comunidades usuárias do serviço e a aldeia em que ele se localiza, gerando um campo fértil para o acirramento de conflitos e disputas preexistentes. No âmbito comunal, os cuidados de saúde são avaliados mais por sua importância sócio-simbólica do que pelo seu poder biológico de curar. Bens e serviços de saúde são inseridos no circuito de trocas cerimoniais entre grupos de parentes, não guardando relações necessárias de correspondência com a razão epidemiológica. d) As formas indígenas de conceber a doença e a saúde definem boa parte das reivindicações levadas aos conselhos. Tais concepções não giram apenas em torno de idéias geradas na cos- 
mologia específica de cada grupo, mas também daquelas incorporadas ao longo do processo colonizatório, que produziu diversos modelos de atenção à saúde, tais como o modelo campanhista, veiculado pelos missionários e pela FUNAI (Fundação Nacional do Índio), o modelo de atenção médica curativa centrado na demanda espontânea individual e, mais recentemente, as propostas preventivistas do Distrito Sanitário Especial Indígena (DSEI). As populações indígenas, assim como outros grupos sociais não-índios, aprenderam a conhecer e a valorizar a medicina curativa. Tal valorização se expressa segundo demandas sempre crescentes de medicamentos, hospitais, laboratórios e outros meios tecnológicos que são encaminhados às organizações indígenas e aos conselhos de saúde, onde se chocam com as prioridades estabelecidas nos planos distritais, que valorizam ações de promoção à saúde e prevenção de doenças. As propostas dos diferentes modelos geram uma gama de discursos sanitários conflitantes entre si, gerando grande dificuldade para os mediadores interétnicos em tornar inteligíveis, para suas bases políticas, as características e diferenças de cada um. O mais comum é a geração de um hiato entre as informações detidas pelos dirigentes e a população comum da aldeia, o que também influi no aporte de apoio político para os mesmos.

\section{A terceirização da saúde indígena e os DSEI}

No outro extremo desse cenário temos as organizações indígenas, um tipo de instituição sem equivalente nos modos tradicionais de organização social indígena, mas não isenta de influência sobre as formas de exercício do poder político nas sociedades que lhes deram origem. Essas entidades vêm construindo um tipo de identidade política centrado na apropriação e utilização de formas institucionais e saberes não-indígenas, mas que permitem um reencontro e um reforço da "comunidade étnica" em busca de seus direitos civis. Além disso, viabilizam a captação de bens, recursos e serviços capazes de contribuir para a redução da assimetria produzida pelo processo colonizatório.

Segundo Albert (2001:198), as transformações verificadas na trajetória das organizações indígenas no Brasil, comportam um deslocamento de lutas políticas centradas “... numa etnicidade estritamente política, embasada em reivindicações territoriais e legalistas, para o que se poderia chamar de etnicidade de resultados, na qual a afirmação identitária se tornou pano de fundo para a busca de acesso ao mercado e, sobretudo ao 'mercado de projetos' internacional e nacional aberto pelas novas políticas descentralizadas de desenvolvimento sustentável". O autor ainda assinala uma retração do Estado no cumprimento de suas obrigações institucionais de representação política e jurídica dos povos indígenas, abrindo caminho para que as organizações desempenhem funções assistenciais em áreas variadas como educação, saúde, vigilância territorial e projetos econômicos diversos.

O processo de implantação dos DSEI, iniciado em 1999, vem seguindo a via da terceirização, concretizada por meio de convênios com entidades não governamentais, sendo muitas delas, organizações indígenas contratadas para a execução integral das ações de saúde. Tal estratégia não encontra correspondente em qualquer outra área do Sistema Único de Saúde (SUS), onde as experiências de terceirização têm se restringido à contratação de serviços em áreas específicas como atividades administrativas, recursos complementares de diagnóstico e prestação de alguns serviços especializados. Tal decisão política restringe o cumprimento dos princípios constitucionais que atribuem ao governo federal a responsabilidade pela gestão do subsistema de saúde indígena.

Analisando as relações entre o Estado e o terceiro setor, Magalhães (2000) demonstra que, no contexto neoliberal brasileiro, vêm se instalando um processo de redução do Estado, com repasse progressivo de suas funções públicas para entidades civis, como as organizações sociais e as atuais "organizações da sociedade civil de interesse público”. Se, por um lado, conforme demonstra o autor, esse processo pode conduzir a um incremento da democratização da sociedade e da capacidade de intervenção nas políticas públicas por grupos civis organizados, por outro lado, tal deslocamento de poder também implica a desconstrução do aparelho estatal. No caso da saúde, essa transformação resulta na impossibilidade de funcionamento adequado do Sistema de Saúde, cuja pulverização de ações e serviços tende a gerar descoordenação, ineficiência e ineficácia. O modelo terceirizado tampouco afasta o risco de corrupção, além de instaurar a necessidade de um acompanhamento técnico minucioso das ações conveniadas, para as quais os órgãos públicos não têm preparo adequado.

Outra importante conseqüência assinalada por Magalhães (2000), é que, ao repassar a responsabilidade da execução, o poder de Estado afasta de si a cobrança dos destinatários do serviço; por sua vez, a entidade civil captadora 
dos recursos passa a sofrer uma dupla pressão, a dos usuários e a do financiador. O autor refere ainda a superposição de papéis do terceirizado, que passa a atuar simultaneamente como organização militante, isto é, em luta pelos direitos sociais e uma organização profissional, ou seja, uma entidade prestadora de serviços, cujo acesso à organização militante procura garantir.

As características descritas por Magalhães são bastante adequadas para direcionar a discussão sobre as relações entre as grandes organizações indígenas da Amazônia brasileira, que assumiram convênios com o Ministério da Saúde (MS) para executar as ações de saúde nas áreas indígenas. O impacto dessa relação pode ser dimensionado ao considerarmos o perfil dos 14 convenentes indígenas na Amazônia (dados de dezembro de 2001): Conselho Indígena de Roraima (CIR), Coordenação das Nações e Povos Indígenas dos Estados de Rondônia, Norte do Mato Grosso e Sul do Amazonas (CUNPIR), Organização Töru Möru (OTM), Conselho Indígena do Vale do Javari (CIVAJA), Federação das Organizações Indígenas do Rio Negro (FOIRN), União das Nações Indígenas de Tefé (UNI-Tefé), União das Nações Indígenas do Acre (UNIAcre), Organização dos Povos Indígenas do Médio Purús (OPIMP), Associação dos Povos Indígenas do Oiapoque (APIO) e COIAB, totalizando mais da metade dos povos indígenas da Amazônia legal.

\section{Considerações finais}

A vinculação das organizações indígenas à proposta de terceirização do MS tem implicações diretas sobre as condições de vida da maior parte dos povos indígenas da Amazônia. A trajetória percorrida por essas entidades mostra, tal como apontou Albert (2000), a superação da fase de denúncias contra a violação dos direitos indígenas que marcaram os primeiros momentos de constituição do movimento indígena e a tomada de decisão de intervir no cenário político por meio de ações concretas, capazes de contribuir para a melhoria das condições de vida dos grupos aldeados. Tal decisão é perfeitamente congruente com as expectativas forjadas, pela base política dessas entidades, em torno do trabalho dos mediadores do contato interétnico, de quem se espera que sejam capazes de captar bens e serviços para redistribuição comunal. As posições publicamente assumidas pelos dirigentes das grandes organizações indígenas da Amazônia, demonstram a necessidade de promover uma mudança nas formas de interação com suas bases políticas, rumo a estratégias de neutralização da desigualdade, sob pena de esvaziamento da retórica política do movimento indígena.

Novas estratégias de ação exigem novos perfis de gerência, demandando a formação de quadros com habilitação técnico-administrativa, capazes de conduzir processos de captação e circulação de bens e serviços que anteriormente não compunham a grade habitual de atuação das organizações indígenas. A trajetória dos dirigentes evidencia um ativo aprendizado da linguagem e estratégias da tecnoburocracia, do manejo de instrumentos administrativos e técnicas de gestão, como via de apropriação da lógica institucional de entidades públicas e de cooperação internacional visando o aprimoramento de suas entidades.

Tal opção não está isenta de riscos, como os já apontados por Magalhães (2000). Na medida em que a organização indígena assume atribuições públicas, recebe também os ônus do contraditório processo de desmanche do Estado brasileiro, assumindo funções constitucionais das quais este tenta se eximir. Atrasos no repasse de recursos, cortes de orçamento, conflitos trabalhistas e problemas decorrentes do mau funcionamento de outros níveis do SUS passam a onerar politicamente a prestadora de serviços, deixando os órgãos de governo à salvo da crítica direta dos usuários. Igualmente não é desprezível a contradição em desempenhar simultaneamente as funções de organização militante e de prestadora dos serviços. O formato peculiar da terceirização da saúde indígena e do funcionamento dos conselhos de saúde transforma a convenente indígena em executora e fiscalizadora de si própria. As enormes responsabilidades geradas pelo exercício dessas funções passa a exigir um grande esforço das pessoas e instituições, a gerar um risco real de relegar outras atribuições das entidades a um plano secundário e de produzir uma burocracia indígena voltada para a condução de processos técnico-administrativos com pouca aderência aos processos político-comunais. Por outro lado, o processo de terceirização aponta para a possibilidade de desconstrução do estigma da tutela e da incapacidade política e intelectual que lhes foi atribuída pelo mundo do “ branco", no processo colonizatório. O reconhecimento das organizações indígenas como parceiras potenciais, por parte do MS, instaura a possibilidade de um protagonismo político, trazendo-as para o centro de uma cenário onde, anteriormente, as instituições indigenistas tentavam relegar a uma posição subordinada.

A análise das falas das lideranças no encontro macrorregional promovido pela COIAB em 
maio de 2000, permite evidenciar as características e motivações dessa trajetória. Segundo o presidente da COIAB, “... nossa idéia desse debate é para discutir o que está acontecendo, problemas que tivemos e a reação de nossas organizações... em alguns lugares tivemos problemas políticos seríssimos com essa coisa de terceirização e neoliberalisamo, mas lá na ponta, na comunidade está o agente de saúde trabalhando com sua radiofonia, os médicos passando por lá, fazendo atendimento, fazendo alguma coisa pelo povo que jamais se viu lá... Com isso algumas organizações não gostaram, disseram que a gente agora tinha contrato e que agora o governo ia ditar regra para fazer o trabalho; que estávamos em risco porque assumimos toda a responsabilidade administrativa e iríamos receber toda a reclamação dos povos... então aparentemente é uma coisa assim tão complicada porque a gente nunca tinha trabalhado nisso, mas se você for perceber, aos poucos o povo e as lideranças, todos estão aprendendo...".

Fica evidente a preocupação de dirigentes que, por força de ofício devem lidar simultaneamente com "localismos" e "globalismos", conjugando intervenções dirigidas a temas muito amplos, como o ônus político de partilhar o processo de terceirização, com a necessidade de desenvolver ações concretas no âmbito comunitário. As formas de intervenção social das lideranças indígenas evidenciam os propósitos de assumir o protagonismo na implantação do modelo de distritalização sanitária indígena. Percebendo também a multipotencialidade do processo planejam obter, por intermédio do mesmo, uma intensificação de bandeiras políticas gerais do movimento indígena.

O processo reflete a concretização de um tipo potencial de autodeterminação, aquela caracterizada por Viveiros-de-Castro (1983:235), como “...idéia (que) sublinha... o caráter de Sujeito dos povos indígenas, sublinha sua diferença ativa; sua capacidade virtual de definir os rumos da própria história. A autodeterminação implica num direito essencial: o direito à diferença, direito difícil de se conceber e de se conceder; de resto, direito que não se concede e sim que se reconhece".

O cenário explicitado pela atuação dos dirigentes das organizações indígenas da Região Norte do Brasil, mostra vitalidade, clareza de propósitos e comprometimento com sua etnicidade, permitindo caracterizá-los, tal como o conceito formula desde o início do texto, como um grupo envolvido na implementação de objetivos coletivos, em busca de obter poderes diferenciados, que os habilitem a perseguir projetos relacionados com a satisfação de tais necessidades, ou seja, como um grupo cujas ações se configuram como de natureza plena e integramente política.

\section{Agradecimentos}

Queremos agradecer à equipe do Distrito Sanitário Especial Indígena, Manaus, que nos franqueou o acesso à correspondência enviada à Coordenação das Organizações Indígenas da Amazônia Brasileira e às lideranças indígenas das organizações da Amazônia, presentes no Encontro Macrorregional e na III Conferência de Saúde Indígena, que autorizaram a gravação de suas falas nesses eventos. 


\section{Referências}

ALBERT, B., 2001. Associações indígenas e desenvolvimento sustentável na Amazônia brasileira. In: Povos Indígenas no Brasil, 1996/2000 (C. A. Ricardo, org.). pp. 197-203, São Paulo: Instituto Socioambiental.

BARTOLOMÉ, M., 1995. Movimientos etnopolíticos y autonomías indígenas en México. América Indígena, 1/2:361-382.

CLASTRES, P., 1978. A Sociedade Contra o Estado. Pesquisas de Antropologia Política. Rio de Janeiro: Francisco Alves.

CLASTRES, P., 1982. A Arqueologia da Violência. Ensaios de Antropologia Política. Rio de Janeiro: Editora Brasiliense.

MAGALHÃES, E., 2000. O Estado e a Saúde Indígena. A Experiência do Distrito Sanitário Yanomami. Dissertação de Mestrado, Brasília: Universidade de Brasília.

OLIVEIRA FILHO, J. P., 1987. Dicionário de Ciências Sociais. 2a Ed. Rio de Janeiro: Editora Fundação Getúlio Vargas.
OVERING, J., 1983/1984. Elementary structure of reciprocity: A comparative note on Guianese, Central Brazilian and Northwest Amazon sociopolitical thought. Anthropologica, 59/62:331-348.

RIVIÈRE, P., 1984. Individual and Society in Guiana. A Comparative Study of Amerindian Social Organization. Cambridge: Cambridge University Press.

SWARTZ, M.; TURNER, V. \& TUDEN, A., 1966. Political Anthropology. Chicago: Aldine.

VIVEIROS-DE-CASTRO, E., 1983. Autodeterminação indígena como valor. Anuário Antropológico, 81: 20-37.

VIVEIROS-DE-CASTRO, E., 1993. Alguns aspectos da afinidade no Dravidianato Amazônico. In: Amazônia: Etnologia e História Indígena (E. Viveirosde-Castro \& M. Carneiro-da-Cunha, org.), pp. 149-210, São Paulo: Universidade de São Paulo/ Fundação de Amparo à Pesquisa do Estado de São Paulo.

Recebido em 5 de junho de 2002

Versão final reapresentada em 25 de novembro de 2002 Aprovado em 2 de dezembro de 2002 